\title{
A good chew or good riddance-How to move forward in the regulation of khat consumption
}

\author{
Axel Klein ${ }^{\mathrm{a}, *}$, Pien Metaal ${ }^{\mathrm{b}}$ \\ a Centre for Health Services Studies, University of Kent, Canterbury, Kent CT27PD, United Kingdom \\ ${ }^{\mathrm{b}}$ Trans National Institute, The Netherlands
}

\section{A R T I C L E I N F O}

\section{Article history:}

Received 7 January 2010

Received in revised form 1 July 2010

Accepted 2 July 2010

Available online 22 July 2010

\section{Keywords:}

Khat

Drug control

Regulation

Drug legalisation

\begin{abstract}
A B S T R A C T
Aims: To review the status of khat, the most recent plant based psychoactive substance to reach a global market, and consider policy making processes in general and the framework of drug control in particular. Materials and methods: Desk review of literature on khat and wider drug policy processes.

Results: The risk assessment and classification of psychoactive drugs is a contested arena where political, economic and moral agendas collide, leaving countries that have banned khat, with significant social costs. To best manage the risks arising from the increasing availability of khat it is therefore suggested to draft a regulatory framework with clear objectives and guiding principles.

Conclusions: Given that medical risks of khat use are modest, the objective of the regulatory framework should be the protection of consumers and community. This is best achieved by establishing processes for the quality control of khat imports, and by regulating access and availability. It should therefore not be considered as a drug to be controlled but as a licit substance that needs to be regulated.
\end{abstract}

(c) 2010 Elsevier Ireland Ltd. All rights reserved.

\section{Introduction}

Up until the 1960 and 1970s khat (Catha edulis Forsk) consumption was confined to the region of production, where traditions of use were well established and had been culturally integrated over centuries (Gebissa, 2004; Anderson et al., 2007). Due to the rapid decomposition of the main psychoactive alkaloids, cathine and cathinone, khat leaves have to reach the consumer within $72 \mathrm{~h}$ of harvesting (ACMD, 2005). Only with the introduction of road, rail and air transport has khat become available well beyond the original khat belt stretching from Yemen, Ethiopia to Kenya. Modern transport has engineered a revolution in consumer behaviour and sparked discussion over the risks and benefits of khat in countries where it had until recent years been unknown. What to do with khat and how best to manage the risks it poses, has over the past few years been subject to discussion in Canada, the US, the UK, the Netherlands, Scandinavia, Ethiopia and Uganda (Klein 2007; Beckerleg, 2006, 2010). Dominated by sectional and professional interest groups, the debate has largely been framed as a drug issue with the discussion focussed on the question of classification according to the legislative control system used in different countries and internationally (ACMD, 2005; WHO, 2006; Fitzgerald, 2009). We argue that the very presentation of khat is critical in determining the direction of the debate. Once the issue is defined

\footnotetext{
* Corresponding author. Tel.: +44 1227 824090; fax: +44 1227824054 .

E-mail addresses: A.Klein@kent.ac.uk, axelcklein@yahoo.com (A. Klein).
}

as a drug problem anchored in the three drug control conventions $(1961,1971,1988)$ the policy determination will ineluctably drift towards prohibiting the substance in question. The last government in the UK demonstrated once more that decisions on drug policy are taken for political reasons, scientific advice is all too often rejected and intolerance flaunted as a moral virtue. ${ }^{1}$

After a century of prohibition and a well funded war on drugs that has lasted for over a generation the notion of 'drug control' has acquired a normalcy rarely questioned outside a narrow circle of drug policy experts (McCoun and Reuter, 2001; Andreas and Nadelmann, 2005; Alexander, 2008). ${ }^{2}$ There are policy makers, community organisers, medical experts and social workers concerned over khat related problems, who see no problem in principle with extending the remit of drug control to this latest of naturally occurring psychoactive substances. This is complacent, as neither the processes of risk assessment and classification, nor the subsequent control measures are straight forward or effective in preventing the problems identified (House of Commons, 2006; Nutt et al., 2007).

\footnotetext{
${ }^{1}$ Examples for this include the recent decisions by the UK government to schedule cannabis and MDMA in higher classes even though experts recommended a lower risk profile. A international example would be the withdrawal of the 1992-1994 WHO cocaine study which the publication of which was blocked by the US ambassador who disagreed with the scientific revision of the risk profile (TNI, 2003).

2 There is a growing literature on drug policy, regular updates on key issues are provided by the Beckley Foundation, TPDF, the DPA and the TNI.
} 


\section{The origins of drug control}

The shortcomings of the 'drug control' system derive from their historical origins. Up until the early 20th century the most widely used psychoactive substances were readily available in most Western countries and the mainstay of compound medicines (Berridge and Edwards, 1987; Jay, 2001). There were concerns over opium deaths and addiction in the UK, and strident campaigns by the medical professions to establish exclusive control over the prescription and sale of medicines. ${ }^{3}$ There was also growing concern over the social dislocation caused by psychoactive drugs, particularly on the working poor, giving rise to social movements like the Temperance League campaigning for total abstinence from all 'intoxicants' (Kerr, 1985; Davenport-Hines, 2001). In the US these campaigns were linked from the start to both progressive and repressive political interests. Alcohol prohibitionists organising as the Anti-Saloon League were allied to organisations fighting for the political enfranchisement of women, and on the other to Klu Klax Klan (Okrent, 2010). The agitation against opium, cannabis and cocaine, on the other hand, was tinged by undisguised racism directed at Chinese, Latinos and African Americans respectively (Musto, 1973; Helmer, 1975; Morgan, 1978).

These national initiatives coalesced at international level in a series of conferences culminating in the creation of the Permanent Central Opium Control Board at the League of Nations in the early 1920 , and a series of treaties restricting the production, distribution and sale of opiates, cocaine and cannabis for non-medical and scientific purpose. After the Second World War the control functions were transferred to different agencies of the United Nations, including the International Narcotic Control Board, the World Health Organisation and the Commission of Narcotic Drugs. A series of treaties provide the foundation of the system, including the 1961 Single Convention on Narcotic Drugs, the 1971 Convention on Psychotropic Substances and the 1988 Convention against Illicit Traffic in Narcotic Drugs and Psychotropic Substances. Around the world governments have introduced tough legislation to repress drug use, administered by drug control bureaucracies, supported by scientific and therapeutic councils and implemented by law enforcement agencies (Bruun et al., 1975; McAllister, 2000; Buxton, 2006).

At national and international level the purpose of the regime is to suppress availability, not to regulate consumption. This has opened a range of problems from the availability of opiates for pain management to self medication with substances like cannabis the therapeutic properties of which have not been recognised by medical establishments. The repression centred drug control model has had profound implications for khat, said by many users to have benefits as an antidepressant (Odenwald et al., 2005, 2007, 2009), an aphrodisiac (Al Motarreb et al., 2002) or as a social lubricant (Weir, 1985; Kennedy, 1987; Gebissa, 2004; Patel et al., 2005; Carrier, 2008). In addition there is some, albeit inconclusive evidence of other positive effects on the periodontium (Hill and Gibson, 1987; Jorgensen and Kaimenyi, 1990) and the production of cardio protective HDL and lower cholesterol levels (Al Habori and Al Mamary, 2004).

\section{Drug classification and khat}

Decisions on the level of control of a drug, the rules for access and distribution and the penalties for breaches are determined by the risk potential attributed to a drug. Three different domains are considered: "the physical harm to the individual user, the tendency of the drug to cause dependence; and the effect of drug use on families,

\footnotetext{
${ }^{3}$ Including the prescription of alcoholic beverages as medicines during alcohol prohibition in the US.
}

communities, and society" (Nutt et al., 2007, p. 1047). Differences in risk are measured according to a tiered regulation system dating back to the 1930s. Both the WHO and the US slot all controlled drugs into Schedules I-IV according to risk and medical benefit. Other systems used by national governments seek to distinguish between 'hard' and 'soft' drugs as in the Netherlands, or between Classes A, B and C drugs in the UK. Expert committees, comprising scientists, police officers, drug experts and medical staff, such as the UK Advisory Council on the Misuse of Drugs, are usually tasked with determining the risk potential.

There is considerable variance over the criteria and respective weighting of drug related harms. One study lists forty-six (McCoun and Reuter, 2001), the ACMD developed a nine parameter matrix, while the Netherlands use 16 discrete items. The very complexity of the process reflects the underlying difficulty of arriving at policy decisions in a field where issues are very broad and not amenable to precise measurement. At the heart of it lie professional opinions by experts involved in the risk scoring process leading to recommendations that are then referred to policy makers.

Over recent years serious flaws in the supposed scientific objectivity of this assessment process have become apparent. In the UK, one comprehensive review of the harm assessment matrix by the ACMD found "no clear distinction between socially acceptable and illicit substances" (Nutt et al., 2007, p. 1049). Alcohol and nicotine ranked in the upper half of the table of substances tested. Expert advice on the downgrading of cannabis and MDMA was rejected by policy makers concerned with 'sending out the right message' on the social acceptability of drug use. The supposed objectivity of scientific assessment is therefore severely compromised by cultural norms, political calculation and moral posturing. While the original intent of UK lawmakers was to leave drug scheduling open to revision in the light of emerging evidence there have only been a single incidence where this has occurred - the temporary downgrading of cannabis under the Home Secretary David Blunkett. Effecting change in an interdisciplinary committee where professions with a clear interest in the existing provisions are represented has been extremely difficult.

A further complicating factor is that drug risk assessments fail to factor in how the interventions themselves affect the risk profile. Where prohibitive legislation fails to eliminate demand, drug use is simply pushed underground (Transform, 2009). This leaves consumers with little or no control over product quality and vulnerable to dangerous practices, such as injecting and/or sharing drug use paraphernalia. A further consequence is the increase in strength of the drug in question, exemplified by the displacement of beer and wine by spirits during alcohol prohibition. The same mechanism has been at work in opiate markets, where opium has been crowded out by heroin (Dikotter, 2004). It furthermore opens a new set of risks relating to criminalisation and the adverse impact of law enforcement. Any discussion over the appropriate level of control has to include the unintended consequence of continuing use post-prohibition.

\section{History of international khat control}

Khat was first brought to the attention of the League of Nations in the early 1930s by a British representative reporting on immoderate consumption in Britain's East African possessions (Bayer, 2005). While attempts to align khat with other banned plant based substances were unsuccessful colonial administrations began to impose restrictions on the sale of khat in the territories under their control: French Djibouti (1956-1957), British Somaliland (1921-1957), South Yemen (1957-1958), Kenya (1945-1956). The motives have been interpreted retrospectively as attempts to either curtail the restive spirit of colonial subjects agitated after long khat 
chewing sessions (Lewis, 1965; Geshekter, 1983) or reverse trade imbalances incurred by rising khat imports made possible by developments in transport (Brooke, 1960). The explanations at the time were that khat use itself contributed to degeneracy and corruption already apparent across rapidly growing colonial settlements. ${ }^{4}$

International efforts were revived in 1956 with the Commission on Narcotic Drugs, the Food and Agricultural Organisation, the League of Arab Nations and the ICAA conducting inquiries into khat (Halbach, 1972). In the 1960s the Expert Committee on Addiction-producing Drugs identified the need for a closer understanding of the chemical and pharmacological principles of khat, and by 1971 the Committee on Narcotic Drugs recommended that the WHO review khat. The subsequent research identified cathine and cathinone as the main psychoactive ingredients (WHO, 1980). Describing the effects of khat chewing as analogous to amphetamine, the two ingredients were assessed as meeting the criteria for control and recommended for scheduling in 1985. Notwithstanding calls by field officers from United Nations agencies and the International Narcotic Control Board to review the status of khat, the situation remains where the extraction of the active ingredients for non-medical purpose is illegal, but the production, distribution and consumption of the vegetable khat is left to national determination (INCB, 2006).

\section{Khat control in different countries}

In the absence of international agreements national governments have developed their own responses. Outside the immediate khat belt this is a very recent issue, a direct consequence of improved communications and international migration (Anderson et al., 2007). These push/pull factors combined with the rising demand for mind and mood altering substances have made khat the latest truly globalised psychoactive substance (Klein et al., 2009). While many countries today have to consider what to do about khat, two patterns of proliferation need to be distinguished. First, there is Diaspora use in the wake of the Somali migration following the collapse of the Somali state and the ongoing civil war. It is this particular European and North American phenomenon that has been the reference point for much of the academic debate. The other, far less widely reported process is the expansion of khat use within Africa. Even in the traditional khat growing countries, cultivation is spreading from areas of customary use, such as Hararghe in Ethiopia, the Meru mountains and North Yemen, to the Ethiopian highlands, the Swahili coast and Yemen's southeast (Gebissa, 2004; Anderson et al., 2007; Carrier, 2007; Gatter, 2009). In addition, khat use, but also cultivation is spreading across the continent into Uganda, Rwanda and South Africa (Andreas, 2008; Beckerleg, 2010).

Countries in the second group tend to look to those in the Europe and North America for leadership, given the imbalance in resources and drug control experience. Yet the question of regulating khat is of far greater import for the khat frontier than for the diaspora. North America and Europe are already well supplied with a wide range of drugs with established fashions and patterns of use. The likelihood of existing drug users switching, or young initiates experimenting with a bundle of leaves of low intensity is highly unlikely. There has been little reported cross over of khat use from the diaspora to the host community with the exception

\footnotetext{
4 The British governor of Somaliland Sir Gerald Reece (1948-1954) for instance, despaired at the lethargy and dissipation that was setting in among vigorous and healthy nomads once they had settled down. Chewing khat was one of those indulgent vices, so the governor worked hard to try and stem its usage. Eventually, he all but abandoned his anti-khat efforts after discovering that all along his driver had been transporting khat in the boot of the Governor's car Charles Geshekter (personal communications).
}

of Israel, where a cathine/cathinone based drug was sold in tablet form (Avrahami, 2004). Even among second generation Somalis in Europe, khat use prevalence is far lower and even then, sporadic (ACMD, 2005; Klein, 2007; Pennings et al., 2008). In Africa, on the other hand, khat use is likely to increase apace, given its easy availability, low production cost, and the urgent need for entertainment in a rapidly urbanizing continent (Klein and Beckerleg, 2007; Beckerleg, 2008).

Decisions for the regulation of khat have, in the main, reflected prevailing drug policy paradigms. Countries with a strong tradition of laissez faire such as the Netherlands and the UK have opted for a regulative system. In the UK, khat is imported as a vegetable, with VAT collected at the point of importation. In support, the Advisory Council on the Misuse of Drugs noted that, inter alia, the "use of the substance is very limited to specific communities within the UK, and has not, nor does it appear likely to, spread to the wider community" (ACMD, 2005, p. 1).

Some members of the community concerned have taken issue with this interpretation and campaigned for khat to be controlled. These campaigns follow a pattern, and are spearheaded by women's groups, supported by Islamic organisations (Grayson, 2004; Patel et al., 2005; Anderson et al., 2007; Fitzgerald, 2009). The main argument has been the social damage caused by khat to the Somali families and communities. Accordingly, men gather to chew khat, spending precious money on this indulgence instead of feeding children, paying for education and maintaining the home. Once intoxicated, they become unable to maintain their commitments and on occasion turn violent on wives and children. In the diaspora, the regular khat chew with other Somali men is said to present a serious obstacle to integration into the mainstream community (Patel et al., 2005; Klein, 2007). UK authorities are even accused of racism for ignoring the plight of Somali communities, or even more sinister, for engaging in the deliberate destruction of Somali men by allowing khat to enter the country freely. Concerns over the drain on household resources are echoed by reports from Somaliland, Yemen and Djibouti (Green, 1999; Borelli and Perali, 2004; World Bank, 2007, 2008).

In countries with strong paternalist or welfare traditions such as Sweden, France, Germany, Norway bans have been effected as a protective measure. Anxiety over Somali family breakdown, linked with the presentation of khat as an un-Canadian activity (Grayson, 2004), swayed Canadian lawmakers to control it in 1997 under the Controlled Drugs and Substances Act, 1998. In the US khat remained off the radar until the doomed intervention by US marines in the Somali relief operation in which several marines got killed. Various commentators quickly established a link between the ferocity of Somali resistance and endemic khat use among militia men. In 1993 the Drug Enforcement Administration classified khat under Schedule 1, and began enforcing this from 2001 onwards as an anti terrorist measure. But the legal validity has been contested by the 4th Circuit Court of Appeal finding that neither the US Code nor the Code of Federal Regulations refers to khat as a controlled substance. Khat importation and possession is therefore treated differently in different parts of the US (Gebissa, 2008).Regulatory regimesKhat consuming countries where khat is toleratedKhat consuming countries where khat is controlledKhat consuming countries where khat status is uncertainAustralia, Ethiopia, Kenya, Netherlands, South Africa, Uganda, UK, YemenCanada, Denmark, France, Germany, Norway, Rwanda, Saudi Arabia, Sweden, Tanzania,US, Israel

In the UK politicians and activists are sometimes heard suggesting that allowing the import of khat as a vegetable, the country is somehow out of step with the rest of the world. This misrepresents khat regulation in particular and drug control in general as a political orthodoxy, when it should be considered much more of a modern experiment that has produced mixed results at best. 
The argument for control is driven by concern over the alleged health risks posed by khat, which is reported to affect cardiovascular, digestive, respiratory, endocrine, and genito-urinary systems. Reported complications include increased blood pressure, tachycardia, insomnia, anorexia, constipation, general malaise, irritability, migraine and impaired sexual potency in men. Mild depressive reactions are associated with khat withdrawal, while frequent high doses can evoke psychotic reactions. Yet the ACMD found that khat use in East Africa and the Middle East was rarely associated with psychiatric morbidity except for those vulnerable through traumatic life experiences, which described many Somalis settled in the UK. Crucially, both physiological and psychiatric effects are based on case reports on samples of heavy and unrepresentative khat chewers. Robust cohort or cross-sectional studies are yet to be conducted.

Moreover, systematic literature reviews (Warfa et al., 2007) and repeated investigations by scientific expert committees have found insufficient evidence for causal relations. In the most recent review the Expert Committee on Drug Dependence of the WHO have concluded, "The level of abuse and threat to public health is not significant enough to warrant international control. Therefore, the Committee did not recommend the scheduling of khat" (WHO, 2006). This echoes the conclusion of the ACMD, "that it would be inappropriate to classify khat... the evidence of harm resulting from khat use is not sufficient to recommend its control" (ACMD, 2005, p. 28). Experts in the Netherlands determined that the abuse potential was low, with negligible dependence effects if measures in terms of tolerance and withdrawal. Moreover, "there is no strong, and even contradictory evidence for a causal relation between khat use and psychiatric morbidity" (Pennings et al., 2008). According to the most recent literature review, "there is an emerging consensus among international health authorities that khat has a low abuse potential. Much of the concern raised about the harmful effects of khat are related to excessive use, associated with adverse social conditions related to displacement and social marginalisation" (Fitzgerald, 2009).

\section{Costs and consequences of inappropriate khat control measures}

Campaigners regularly present khat bans as cost free and unproblematic, largely because as community activists and Islamic scholars they have little experience of drug control. Yet the unintended consequences, such as organised crime, the criminalisation of young people, police corruption and rising prison populations, are now even being recognised as a major problem by the international drug control bureaucracy itself(McCoy, 2004; Bewley Taylor, 2003; Lines, 2007; Costa, 2008). Moreover, the experience of drug control in the main theatres of the war on drugs first declared by Richard Nixon in 1973 has been pitiful. Across North America and Europe the use of illegal drugs far from having been eliminated has become deeply entrenched and 'normalised' among young people. Governmental decisions to restrict the distribution of drugs which are popular, considered relatively harmless by the majority of users, and are rooted in cultures of consumption are chronically unsuccessful. And of particular import for khat producers is the impact that drug bans have had on the governance of weak states, from Afghanistan to Guinea Bissau to Mexico.

In the case of khat control in the diaspora the costs of control measures include the (i) criminalisation of Somali communities and deterioration in police-community relations and (ii) the criminalisation of the khat trade, leading to the organisation of criminal groups and diversification into other criminal activities. This is borne out by the Canadian experience, where a series of police raids on suspected khat dealers in 1999 led to a series of wrongful arrests and serious injuries of suspects. In Toronto Somali community events were targeted by members of the drug squad, provoking repeated altercations between police officers and Somali men, a public confrontation at a west-end shopping plaza in July 2001, and regular sweeps on known Somali restaurants and cafes (Grayson, 2004). One of the most resented policing practices was instructing older men to open their mouths to check for khat (Anderson et al., 2007).

In Sweden, the criminalisation of khat has established a khat market that is far closer in resemblance to the illicit markets for cocaine and cannabis than the khat café culture that prevails in the UK, the Netherlands, Yemen or Kenya. Word of the arrival of khat is spread by khat dealers and their runners to potential buyers. Deals are made in car parks, under the threat of violence and arrest, with no time for inspecting the quality of the goods. Prices are non-negotiable, and both parties worry about being ripped off or burnt. With nowhere to go, khat users chew in parks, while walking in the street, or in apartments let out by their tenants for khat chewing sessions. Khat suppliers risking prison sentences and fines have diversified into cannabis and cocaine, establishing international networks with suppliers in the Netherlands and the UK (Anderson et al., 2007).

The benefits of these controls are yet to be seen, as the key problems faced by the Somali community-low educational attainment, high unemployment, family breakdown, low levels of social mobility, have not been addressed either in Canada or in Sweden. It may well be that the focus on banning khat distracts both community and policy makers from the far more important issues of structural marginalisation and complex gender relations. Indeed, khat, far from proving an obstacle, may even provide a route to community advancement by providing a structured setting for socialisation and an opportunity for entrepreneurs. This pattern is at least partially suggested by the migration flow of diaspora Somalis from Sweden to the UK (Klein, 2008).

Prohibitions of khat have furthermore, failed to eliminate either demand or supply. In Toronto, khat chewers were observed to be spending an entire day chasing a cargo across the city. Prices for bundles trading at $£ 3.00$ in London shoot up to $C \$ 50$, for a poorer quality product. In Israel, where a Yemeni community continues to import khat, a substitution effect has been reported with the production of hagigat, Hebrew for party-khat, a capsule containing $200 \mathrm{mg}$ of cathinone. There is little epidemiological information and no social research on consumption patterns, but reported complications include acute myocardial ischemia, pulmonary edema, and intracerebral hemorrhage. The authors assume that these effects result from the much higher levels of cathinone (Bentur et al., 2008), to which we add the removal of protective factors that inhere in the traditional mode of administration, where uptake is gradual and the opportunities for overdose reduced by the sheer volume of vegetable matter required. Recent trends in the UK, where "mephedrone has emerged from nowhere to become the fourth most popular drug amongst British clubbers in 2009" (Measham et al., 2010) have further alerted to the possibility of khat based synthetic drugs crossing drug use communities, though the rebound on original chewing communities is yet to be studied. Destroying existing cultures of consumption carries the risk of further destabilizing vulnerable populations by driving them towards illicit markets where more intense products are traded in less secure environs.

\section{Drafting an appropriate regulative framework}

Approaching khat as a drug control issue carries substantial social costs without coming near resolving any of the underlying problems. The examples of Canada and Sweden suggest that any equivalence between khat and cocaine will leave the Somali com- 
munity in a far more marginalised position than before. At the same time, community activists also deserve the right to be given voice in the determination of the regulative framework. So far the discussion has focussed on khat importing countries, where consumption is limited to ethnic minorities. In the khat belt, and particularly in Yemen, Somaliland and Djibouti social forms of regulation have given way to ever more pervasive patterns of consumption. The principles for khat regulation suggested below concerns distribution and consumption and applies to all countries.

They follow, first, from the premise that access and use of psychoactive substance is subject to regulation in all society, and second, that attempts to suppress established cultures of consumption in market economies creates insupportable social costs. The objective of regulations has to be to ensure the maximum protection of consumers, their families and the wider community. Care has to be taken to distinguish these objectives from political, moral or religious objectives. Regulative frameworks should not be vehicles of sectarianism or proxies for moral or political agendas. The overarching principle is therefore the reduction of khat related harm and the management of risk. It is therefore suggested to look at restricting access across different dimensions, marked by space, time, person-status and product - or, to give it interrogative pronouns - where, when, who and what.

\subsection{Where}

The sale and public consumption of khat like any other psychoactive product should be reserved to licensed traders and premises. The licensing of khat retail has to be formulated in accordance with the economic realities and traditions of each country. In Streatham, a part of inner London with a large Somali population, the council took vigorous action against street traders selling khat from the boot of parked cars, but left alone and protected, the operation of two mafrishes (Klein, 2008). In the khat belt the main focus would fall on places of consumption. Important is the direction of travel, to signal to all parties that the objective is not, as in the case of say anti smoking campaigns, to move to abstinence, but for establishing controlled environments. Examples are the bans on khat chewing in public offices introduced in Yemen in 2002 (World Bank, 2007), which could be extended to public spaces (at least at certain hours), moving vehicles, educational establishments and so on. Important with any licensing regulation is the level of enforceability. Unenforceable bans are the worst of all options as they bring all government efforts into disrepute.

In the UK khat is currently sold in mafrishes, cafes run by Somalis for the chewing of khat. In these tea and food are often served, some provide pool tables, others have satellite TV and Arabic language newspapers. We also propose the licensing of mafrishes, which at the moment, in the UK at least, operate in a legal twilight zone. There is no reason why they should not be subject of the same health and safety control regulations as any other catering business. The other side of the coin of regulative mainstreaming is also of importance with respect to citizenship and inclusion. Somali customers of these establishments should be afforded and come to expect, the same protection and service from the regulator as the patrons of any other business in the hospitality industry.

\subsection{When}

All service providers are subject to regulated and strictly monitored trading hours. In the UK, mafrishes because of their anomalous status often escape closer scrutiny resulting in erratic opening hours. In many cases the mafrish closes only after the last customer leaves, giving rise to stories of groups of highly animated Somali men spilling into the street late at night to disturb local residents. Once again, a more scrupulous adherence to local trad- ing standards is required of both mafrish management and local agencies. Bringing mafrish opening times into line with restaurants, cafes and pubs should help address one of the main concerns in the diaspora, that khat chewing has become of part of a $24 \mathrm{~h}$ city lifestyle.

This is even more important for the khat belt itself, where the steady extension of khat use is widely lamented for reducing productivity and undermining social morals. Here the time zones for khat use and sale could be used effectively. Prior to unification in 1993, the sale of khat in Aden was restricted to weekends. This provided one good example of how harm can be contained and demand curtailed by managing the supply. But the most important thing is to use regulations to reinforce social convention and bring khat use into a rhythm that is compatible with the demands of work and family life.

\subsection{Who}

There is wide consensus that minors should be prevented from purchasing or consuming khat in public places. In the diaspora this is not much of an issue, as most young people of Somali, Yemeni and Ethiopian extraction follow a mainstream pattern of drug experimentation, with the exception of alcohol. In the khat belt, however, traditional values of age based restrictions have to be applied more rigorously. Further elaborations could be made to give recognition to the existence of problem users, and to oblige mafrish owners not to sell to people who seem unduly intoxicated.

But the most provocative of our suggestions is that mafrishes in the UK and other parts of Europe have to operate by the standards of the host country. The gender barrier in existence today, where women who visit a mafrish are stigmatised and harassed, is not tolerable. If the real issue is integrating into the mainstream mafrishes have to make female guest welcome and provide facilities for them. Regulators can help by insisting on female toilets and if need be, separate areas.

\subsection{What}

There is rising concern over the different inputs going into the cultivation of khat. At present, there are no controls for chemical residues even though there is ample anecdotal information about farmers non-compliance with health and safety guidelines, often due the lack of information. There is little research into the health problems arising from chemical poisoning, but a number of measures could be taken to raise safety standards; (i) chemical assays along the entire commodity chain, including wholesale markets, national points of entry, retail markets and mafrishes; (ii) information about chemical hazards to khat farmers; and (iii) information campaigns about reducing hazards, e.g. washing, to consumers.

\section{Conclusion}

This framework is in line with existing regulations for the distribution and sale of most licit items of consumption, be these psychoactives like alcohol or tobacco products, tea, coffee, or food. They are an attempt to move the discussion on khat out of the maelstrom of drug classification and drug control, so as to open the way for a realistic management model. In conclusion we would like to add a number of guiding principles for any national or international regulatory framework:

(1) The regime is put into place to protect individuals, families and communities - not for the benefit of professional interest groups. 
(2) The regime has to be based on practical, realisable goals that factor in the costs of the regulation.

(3) The objective is to protect public health and social well being not to pursue ideological ambitions, like abstinence or a 'khat free world'.

(4) The regime must have feedback loops and flexibility to adapt and change with times.

\section{References}

Advisory Council on the Misuse of Drugs, 2005. Khat (Quat): Assessment of Risk to the Individual and Communities in the UK. Home Office, London.

Al Habori, M., Al Mamary, M., 2004. Long-term feeding effects of Catha edulis leaves on blood constituents in animals. Phytomedicine 11,639-644.

Al Motarreb, A., Baker, K., Broadley KJ, 2002. Khat: pharmacological and medical aspects and its social use in Yemen. Phytotherapy Research 16, 403-413.

Alexander, B., 2008. The Globalisation of Addiction. A Study in the Poverty of Spirit. Oxford University Press, Oxford.

Anderson, D.M., Beckerleg, S., Hailu, D., Klein, A., 2007. The Khat Controversy: Stimulating the Drugs Debate. Berg, Oxford.

Andreas, P., Nadelmann, E., 2005. Policing the Globe. Criminalization and Crime Control in International Relations. Oxford University Press, Oxford.

Andreas, C., 2008. Prohibition through the back door: khat in South Africa. Unpublished paper, Strathclyde University.

Avrahami, I., 2004. A Qat above the rest. Haaretz, 2006.

Bayer, I., 2005. A Drogok és emberek - múlt, jelen, jövo. Budapest Gyógyszerésztudományi Társaság, 2005.

Beckerleg, S., 2006. What Harm: Kenyan and Ugandan perspectives on khat. African Affairs 105, 219-241.

Beckerleg, S, 2008. Khat special edition introduction. Substance Use and Misuse 43 , 749-761.

Beckerleg, S., 2010. Ethnic Identity and Development: Khat and Social Change in Africa. Palgrave Macmillan, New York.

Bentur, Y., Bloom-Krasik, A., Raikhlin-Eisenkraft, B., 2008. Illicit cathinone ("Hagigat") poisoning. Clinical Toxicology 46, 206-210.

Berridge, V., Edwards, G., 1987. Opium and the People: Opiate Use in Nineteenth Century England. Yale University Press, Newhaven/London.

Bewley Taylor, D., 2003. Emerging policy contradictions between the United Nations drug control system and the core values of the United Nations. International Journal of Drug Policy 16, 423-431.

Borelli, S., Perali, F., 2004. Drug consumption and intra-household distribution of resources. In: Dagum, C, Ferrari, G. (Eds.), Household Behaviour, Equivalence Scales, Welfare and Poverty. Physica-Verlag, Heidelberg.

Buxton, J., 2006. The Political Economy of Narcotics: Production, Consumption and Global Markets. Zed, London.

Brooke, C., 1960. Khat (Catha edulis): its production and trade in the Middle East. Geographical Journal, 126.

Bruun, K., Pan, L., Rexed, I., 1975. The Gentlemen's Club: International Control of Drugs and Alcohol. Chicago University Press, Chicago.

Carrier, N., 2007. Kenyan Khat: The Social Life of a Stimulant. Brill, Leiden.

Carrier, N., 2008. Is Miraa a drug? Categorizing Kenyan khat. Substance Use and Misuse 43, 803-818.

Costa, A., 2008. Making drug control 'fit for purpose': Building on the UNGASS decade. http://www.unodc.org/documents/commissions/CND-Session51/CNDUNGASS-CRPs/ECN72008CRP17.pdf.

Davenport-Hines, R., 2001. The Pursuit of Oblivion: A Social History of Drugs. Phoenix Press, London.

Dikotter, F., Laamann, L., Xun, Z., 2004. Narcotic Culture: A History of Drugs in China. Hurst and Company, London.

Fitzgerald, J., 2009. Khat: a literature review. Centre for Culture, Ethnicity and Health, Melbourne. Available at: http://www.ceh.org.au/downloads/ Khat_report_FINAL.pdf (accessed 02.01.10).

Gatter, P., 2009. The political economy of Quat in Yemen. In: Conference Paper at The Changing Use and Misuse of Catha edulis (Khat) in a Changing World: Tradition, Trade and Tragedy, Scandic Linköping Väst, Linköping, Sweden, 6 October.

Gebissa, E., 2004. Leaf of Allah: Khat \& Agricultural Transformation in Hararge, Ethiopia 1875-1991. James Currey, Oxford.

Gebissa, E., 2008. Scourge of life or an economic lifeline? Public discourses on khat (Catha edulis) in Ethiopia. Substance Use and Misuse 43, 784-802.

Geshekter, C., 1983. Entrepreneurs, livestock and politics: British Somaliland 1920-1950. In: Coquery-Vidrovitch, C. (Ed.), Entreprise et Entrepreneurs en Afrique: XIXe et XXe Siècle. Editions L'Harmattan, Paris, pp. 270 289.

Grayson, K., 2004. Drug khat astrophe: khat and Somali Canadians. In: Howell, A. (Ed.), Governance and Global Disorders: Trends, Transformations and Impasses. York University Press, Toronto, Canada.

Green, R.H., 1999. Khat and the realities of Somalis: historic, social, household, political and economic. Review of African Political Economy 79, 33-50.

Halbach, H., 1972. Medical aspects of the chewing of khat leaves. Bulletin of the World Health Organisation, 47.

Helmer, J., 1975. Drugs and Minority Oppression. Seabury, New York.

Hill, C.M., Gibson, A., 1987. The oral and dental effects of q'at chewing. Oral Surgery, Oral Medicine, Oral Pathology, Oral Radiology and Endodontology, 433-436.
House of Commons Science and Technology Committee, 2006. Making a hash of it? Fifth report of session 2005-2006. Stationary Office, London. http//www. publications.parliament.uk/pa/cm200506/cmselect/cmsctech/1031/103102. htm (accessed 01.05.07).

International Narcotic Control Board, 2006. Annual Report. United Nations, Vienna. Jay, M., 2001. Emperors of Dreams: Drugs in the Nineteenth Century. Dedalus, London.

Jorgensen, E., Kaimenyi, J.T., 1990. The status of periodontal health and oral hygiene of Miraa (Catha edulis) chewers. East African Medical Journal 67, 585590 .

Kerr, A., 1985. Organized for Prohibition: A New History of the Anti-Saloon League, New Haven, CT.

Kennedy, J.G., 1987. The Flower of Paradise: The Institutionalized Use of the Drug Qat in North Yemen. Reidel Pub Co, Dordrecht, Lancaster.

Klein, A., 2007. Khat and the creation of tradition in the Somali diaspora. In: Fountain, J., Korf, D.J., Fountain, J.(Eds.), Drugs in Society: A European Perspective. Radcliffe Publishing, Oxford.

Klein, A., 2008. Khat in the neighbourhood - local government responses to khat use in a London community. Substance Use and Misuse 43, 819-831.

Klein, A., Beckerleg, S., 2007. Building Castles of Spit - The Role of Khat Chewing in Worship, Work and Leisure. In: Goodman, J., Lovejoy, P., Sherrat, A. (Eds.), Consuming Habits. Routledge, London.

Klein, A., Beckerleg, S., Hailu, D., 2009. Regulating khat - dilemmas and opportunities for the international drug control system. International Journal of Drug Policy 20.

Lewis, I.M., 1965/2002. A Modern History of the Somali. Nation and State in the Horn of Africa. James Currey, Oxford

Lines, R., 2007. Death Penalties for Drug Offences: A Violation of International Human Rights Law. International Harm Reduction Association, IHRA, London.

McAllister, W., 2000. Drug Diplomacy in the Twentieth Century: An International History. Routledge, London.

McCoun, R., Reuter, P., 2001. Drug War Heresies: Learning from Other Vices, Times and Places. Cambridge University Press, Cambridge.

McCoy, A.W., 2004. The stimulus of prohibition: a critical history of the global drug trade. In: Steinberg, M., Hobbs, J., Mathewson, K. (Eds.), Dangerous Harvest: Drug Plants and the Transformation of Indigenous Landscapes. Oxford University Press, Oxford

Measham, F, Moore, K., Newcombe, R., Welch, Z., 2010. Tweaking, bombing, dabbing and stockpiling: the emergence of mephedrone and the perversity of prohibition. Drugs and Alcohol Today 10.

Musto, D., 1973. The American Disease: The Origin of Narcotic Control. Yale University Press, New Haven.

Morgan, P., 1978. The legislation of drug law: economic crises and social control. Journal of Drug Issues 8, 53-62.

Nutt, D., King, L., Saulsbury, W., Blakemore, C., 2007. Development of a rational scale to assess the harm of drugs of potential misuse. The Lancet 364, 10471053.

Odenwald, M, Neuner, F., Schauer, M., Elbert, T., Catani, C., Lingenfelder, B., Hinke, H., Hafner, H., Rockstroh, B., 2005. Khat use as risk factor for psychotic disorders: a cross-sectional and case-control study in Somalia. BMC Medicine 3, 5.

Odenwald, M., Hinkel, H., Schauer, E., Neuner, F., Schauer, M., Elbert, T., Rockstroh, B., 2007. The consumption of khat and other drugs in Somali combatants: a cross-sectional study. PLoS Medicine 4.

Odenwald, M., Hinkel, H., Schauer, E., Schauer, M., Elbert, T., Neuner, F., Rockstroh, B., 2009. Use of khat and posttraumatic stress disorder as risk factors for psychotic symptoms: a study of Somali combatants. Social Science and Medicine 69, 1040-1048.

Okrent, D., 2010. Last Call The Rise and Fall of Prohibition. Scribner, New York.

Patel, S., Wright, S., Gammampila, A., 2005. Khat Use among Somalis in Four English Cities. Home Office, London.

Pennings, E.J., Opperhuizen, A., van Amsterdam, J.G., 2008. Risk assessment of khat use in The Netherlands. A review based on adverse health effects, prevalence, criminal involvement and public order. Regulatory Toxicology and Pharmacology $52,199-220$.

TNI, 2003. An Agenda for Vienna: Change of Course. Drugs \& Conflict Debate Papers 6. Transnational Institute, Amsterdam.

Transform Drug Policy Foundation, 2009. After the War on Drugs: Blueprint for Regulation. TPDF, Bristol.

Warfa, N., Klein, A., Bhui, K., Leavey, G., Craig, T., Stansfeld, S., 2007. Association between khat use and mental disorders: an emerging paradigm. Social Science and Medicine 65, 309-318.

Weir, S., 1985. Qat in Yemen: Consumption and Social Change. British Museum Publications, London.

World Health Organization Advisory Group, 1980. Review of the pharmacology of khat. Bulletin on Narcotics 12 (special issue devoted to Catha edulis (khat)).

World Health Organization, 2006. ECDD 2006/4.4 Assessment of khat (Catha edulis Forsk). World Health Organisation, Geneva. http://www.who.int/medicines/ areas/quality_safety/d.dKhatCrit.Review.pdf.

World Bank, 2007. Yemen: Towards Quat Demand Reduction. Report No. 39738. WB, Washington.

World Bank, 2008. Somali joint needs assessment: Somali Reconstruction and Development Programme. http://www.somali-jna.org/index.cfm?module= ActiveWeb\&page=WebPage\&s=rdp_implementation_i (accessed 03.18.09). 